\title{
Physicians aplenty in Nova Scotia
}

A n extraordinarily generous fee schedule? The bustling lure of a port city? More bars per capita than any other city in the country?

It seems nothing so charming lies at the root of Nova Scotia having more physicians per capita than any other province, although it appears the fee schedule does offer some advantages.

Medical administrators say the reason Nova Scotia has 231 physicians per 100000 population, as compared with the Canadian average of 201, has to do with things like government recruitment initiatives and the quality of health facilities.

The government points to its recruitment and retention efforts as the root of the province's largesse. "We have been looking at how to attract physicians and keep them here," says Angela Purcell, acting director of physician services with the department of health.

The department has a full-time physician recruitment coordinator and has created Health Team Nova Scotia, a website devoted exclusively to recruitment. The site sells the province as a place where physicians can find balance in their lives. "It says to me we're doing something right, and we're doing something well," Purcell says. "For many years, as with most provinces, we were struggling to attract physicians and keep them here."

The local training environment and the presence of the Dalhousie University medical school in Halifax also appear to play a major role.

"We have a great medical school and teaching hospitals," says Dr. Jane Brooks, president of Doctors Nova Scotia. "We know locally trained physicians are more likely to stay in the area."

Dalhousie has access to more than 100 teaching sites across the Maritimes, including nine affiliated teaching hospitals, in which to place its students. The medical school, which was founded in

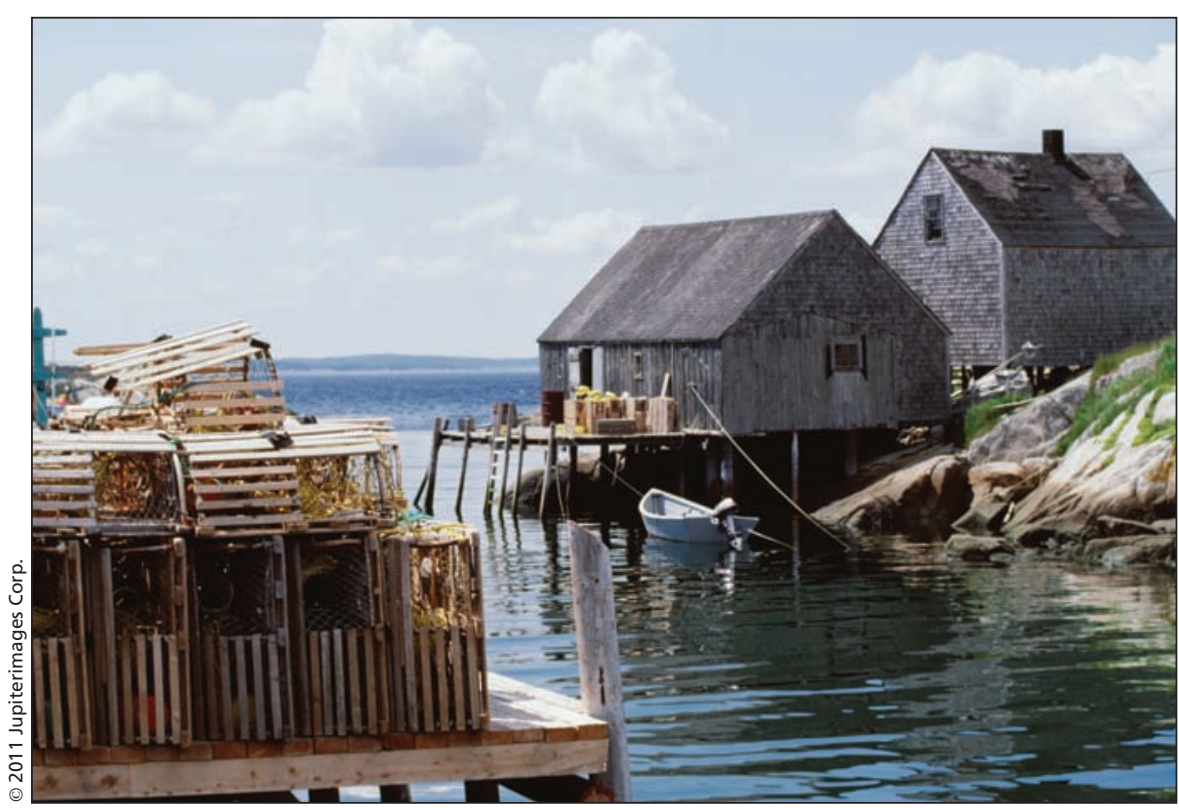

Nova Scotia has 231 physicians per 100000 population, as compared with the Canadian average of 201.

1868, also lays claim to more than 1300 faculty members, upwards of 400 undergraduates, and roughly 450 residents.

Brooks says Halifax's large health care facilities, in particular the IWK Health Centre and the Queen Elizabeth II Health Sciences Centre, are another key factor in attracting physicians. "We have more sub-specialties because of two tertiary care hospitals. That leads to more referrals."

The opportunity for physicians to earn money through alternative payment plans are another draw, Purcell notes. In the current master agreement between physicians and the province, incentives are offered for such things as having a practice open in the evenings and on weekends.

"It's pretty different from how we paid physicians historically," Purcell says. "We used to be focused on fee codes. The new agreement focuses on aligning incentives."

Others say the Canada Institute of
Health Information (CIHI) numbers that indicate Nova Scotia has the highest number of physicians may be deceptive. The CIHI numbers don't indicate how many of those doctors are actually practising, says Dr. Tom Marrie, dean of the Dalhousie medical school. "I'm included but I don't practise."

The numbers also don't reflect fulltime employment, Brooks says. "My sense is that we have a fairly large number of part-time physicians."

Others simply find the CIHI numbers bemusing.

"I hear constantly complaints that patients can't find a family doctor, and our waiting times are the worst in Canada," says Dr. Mark Kazimirski, a family physician in Windsor, NS and chief of staff at the Hants Community Hospital. "I can only grieve for the rest of Canada, if we're the best." — donalee Moulton, Halifax, NS

CMAJ 2011. DOI:10.1503/cmaj.109-3787 